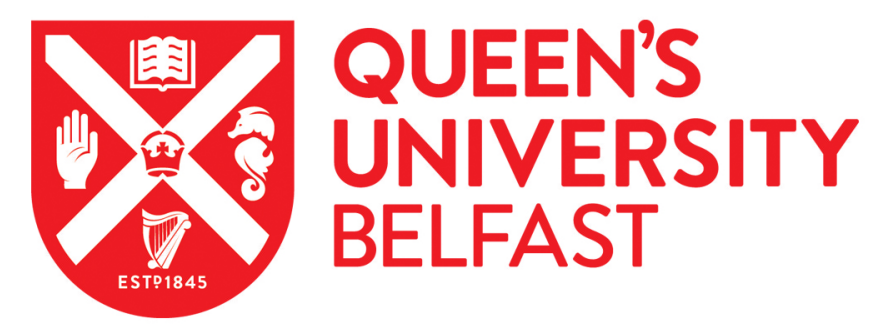

\title{
Production of solid biofuel granules from drum granulation of bio- waste with silicate-based binders
}

Chen, H., Mangwandi, C., \& Rooney, D. (2019). Production of solid biofuel granules from drum granulation of bio-waste with silicate-based binders. Powder Technology, 354, 231-239.

https://doi.org/10.1016/j.powtec.2019.05.074, https://doi.org/10.1016/j.powtec.2019.05.074

Published in:

Powder Technology

Document Version:

Peer reviewed version

Queen's University Belfast - Research Portal:

Link to publication record in Queen's University Belfast Research Portal

Publisher rights

(C) 2019 Elsevier B.V

This manuscript version is made available under the CC-BY-NC-ND 4.0 license http://creativecommons.org/licenses/by-nc-nd/4.0/,which permits distribution and reproduction for non-commercial purposes, provided the author and source are cited.

\section{General rights}

Copyright for the publications made accessible via the Queen's University Belfast Research Portal is retained by the author(s) and / or other copyright owners and it is a condition of accessing these publications that users recognise and abide by the legal requirements associated with these rights.

Take down policy

The Research Portal is Queen's institutional repository that provides access to Queen's research output. Every effort has been made to ensure that content in the Research Portal does not infringe any person's rights, or applicable UK laws. If you discover content in the Research Portal that you believe breaches copyright or violates any law, please contact openaccess@qub.ac.uk. 


\section{Production of solid biofuel granules from drum}

\section{granulation of bio-waste with silicate-based}

\section{binders}

Haili Chen ${ }^{\text {a }}$, Chirangano Mangwandi ${ }^{a^{*}}$, David Rooney ${ }^{\text {a }}$

${ }^{\text {a }}$ School of Chemistry and Chemical Engineering, Queen's University Belfast, Belfast, BT9 5AG, Northern Ireland

Corresponding Author e-mail; c.mangwandi@qub.ac.uk

Tel: +4428909744378 


\section{Abstract}

Herein compost was selected as a model bio-waste substrate to make solid biofuel granules using wet drum granulation and a sodium silicate binder. Using a laboratoryscale drum granulator (300 g/batch), spherical compost granules within the targeted size range (3.35 - $14 \mathrm{~mm})$ could be produced with a good compressive strength in good to excellent yields. The effects of compost moisture content, process parameters (drum speed, granulation time) and binder parameters (binder concentration, binder to compost ratio) on the properties of the resulting granules (size distribution, bulk density, compressive strength, water resistance, gross calorific value, ash content) were investigated. The optimal conditions for producing granules as a solid biofuel with competitive properties when compared with woody biomass fuels were achieved by applying a drum rotational speed of $32-37 \mathrm{rpm}$, granulation time of $15 \mathrm{~min}$, sodium silicate solution $1-3 \mathrm{wt} \%$ and binder to solid ratio $0.77-0.90$.

\section{Graphical abstract}

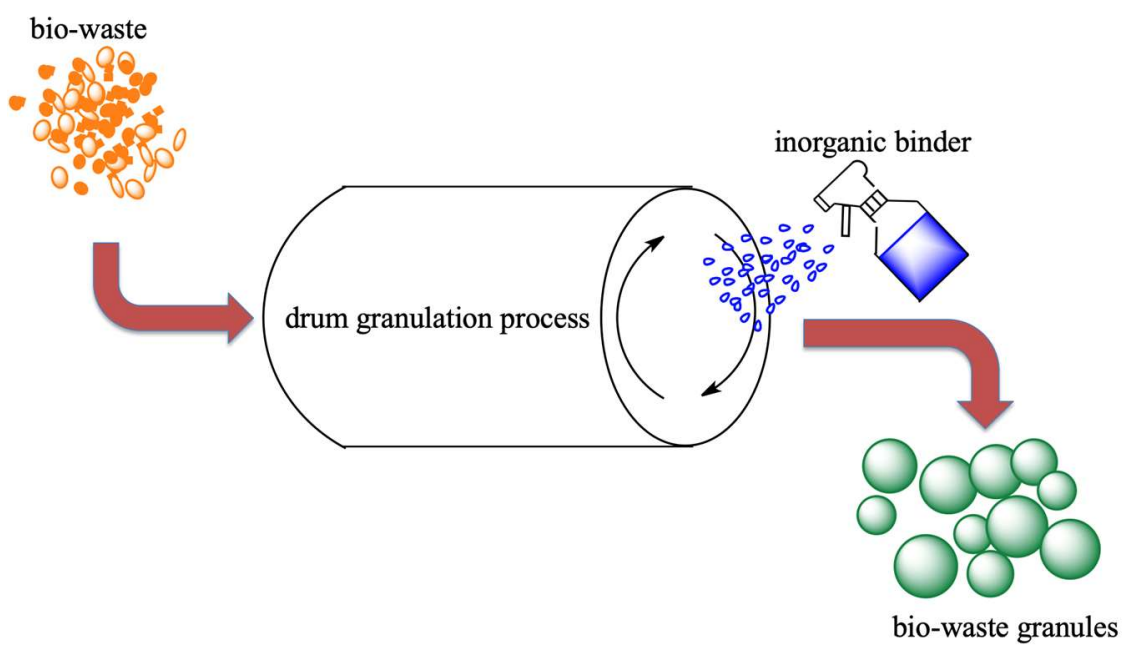




\section{Highlights}

- Soluble sodium silicate binder was successfully applied for compost granulation.

- The link between the properties of granules and the conditions of granulation process was established

- Granules produced had the competitive properties with woody fuels.

\section{Key words}

Drum granulation, sodium silicate, compost, size distribution, granule properties 


\section{Introduction}

Biomass fuels contain a large amount of energy and produces low acidic gas emissions with no net carbon dioxide $[1,2]$. It has become one of the most valuable renewable energy resources to reduce the usage of fossil fuels and greenhouse gas emissions in our modern society. It was reported that biomass alone would occupy $20 \%$ of the global primary energy supply in 2030 which is twice that of 2010 , and the overall would account for $60 \%$ of global renewable energy consumption [3].

One form of biomass, namely bio-waste (forest, agricultural and urban wastes) is an increasing threat to the human society [1]. By managing the bio-waste properly, many could be reused as a resource for energy generation and provide substantial benefits for both human beings and environment $[4,5,6]$. With the recent implementation of the renewable heat incentive (RHI) scheme, the use of biomass fuels in UK has started to expand and biomass installations which use renewable sources to provide heat and power are expected to grow [7]. Therefore, the production of biomass fuels from bio-waste could provide an alternative or supplement to the traditional wood fuels. However, due to their low bulk density, softness and irregular shapes, many problems can arise during transportation, storage and utilisation. For example, the bulk density of loose straw was found to be only about $20-40 \mathrm{~kg} / \mathrm{m}^{3}$, and that of woody resources like wood sawdust and small chips were about $120-200 \mathrm{~kg} / \mathrm{m}^{3}$ [8]. To overcome these limitations, densification is proposed as a solution to produce biomass products with more desirable properties (high bulk density, high strength and better flowability etc.), which can subsequently reduce the cost of transportation and also make further utilisation more convenient. 
Compared with pressure agglomeration, agglomeration by granulation can save process energy input and provide easier scale-up while increasing the flowability and bulk density of biomass [9]. Granulation is widely used for mineral processing and industries for making detergents, pharmaceuticals, food products and fertilisers [10]. During the wet granulation process, raw materials are combined with liquid binders and subjected to rolling or tumbling forces to form loose agglomerates (granules) in equipment such as balling discs, balling cones, and balling drums [9]. Recently, wet granulation has also emerged as a technique for biomass agglomeration. Ghasemi et al. made compost granules with the high bulk density over $700 \mathrm{~kg} / \mathrm{m}^{3}$ through drum granulation method using sugar beet molasses as the binder $[11,12]$. Yandapalli and Mani found that pine wood powders could be successfully densified into good quality granules by a pan granulator using a starch solution as binder [13]. Also switchgrass was used to make granules by this group using a starch - sodium alginate as binder [14]. Moreover, drum granulation of biochar powders using hydroxypropyl methylcellulose solution as binder was carried out by Bowden-Green and Briens [15]. Among these reports, organic binders such as starch and sugar molasses are commonly used for biomass agglomeration. To the best of our knowledge that there has been no study of using inorganic binders for biomass granulation. Soluble sodium silicate binders, known as water glass, have been widely used in industries due to its low cost, odourless nature and non-toxicity [16]. Without the handling, safety and environmental issues, they also offer a higher level of binding performance such as strength, durability and water resistance [17]. This water resistance offers significant advantages over water soluble binders used in other studies particularly when considering deployment of the technology in wetter climates. Such inorganic binders have been used successfully to consolidate fines or small particles into larger 
units in the processes of agglomerating bentonite, detergent, iron ore, silica and coal [18, $19,20]$. In this study, we have investigated the possibility of using an inorganic silicatebased binder in a drum granulation process for the production of bio-waste granules using compost as the model bio-waste. The physical properties of the fuel granules produced were analysed, and the link between the properties of granules and the processing and binder parameters was established.

\section{Materials and methods}

\subsection{Materials}

\subsubsection{Compost and wood pellets}

Commercial potting compost Miracle - Gro was purchased from The Scotts Company (UK) Ltd. This commercial compost was a mixture of woody plant material (dry leaves, small wood chips, straw etc.), waste materials (food scraps, newspaper etc.) and large fragments (stones, branches). Before granulation, the compost was left in the lab to dry at room temperature and sieved using a standard sieve with mesh size $2.8 \mathrm{~mm}$ to remove the large fragments. After sieving, distilled water was added to the sieved compost to reach a moisture content $(52-61 \mathrm{wt} \%)$ and then the compost was sealed in a plastic bag for at least 2 days before granulation. The compost used in this study was from three different batches and labelled as Compost A, B, C. The details of the compost used are shown in Table S1. Commercial wood pellets were purchased from Woodlets.

\subsubsection{Binder}

Sodium silicate binders ( $1 \mathrm{wt} \%, 3 \mathrm{wt} \%, 5 \mathrm{wt} \%, 7 \mathrm{wt} \%$ and $9 \mathrm{wt} \%)$ were prepared by 
diluting commercial sodium silicate solution $(36 \mathrm{wt} \%$ Q70/79, molar ratio $>3.2$, Central Chemical Supplies Limited) with distilled water. Polyethylene glycol (supplied by Sigma Aldrich, $M_{\mathrm{n}}$ 3350) was added as a wetting agent to the diluted sodium silicate binders with the final polyethylene glycol concentration of $0.5 \mathrm{wt} \%$.

\subsection{Granulation}

Granulation experiments were carried out at room temperature in a PVC drum (Fig. 1, right) with a length of $65 \mathrm{~cm}$ and a diameter of $38 \mathrm{~cm}$. The drum contained only one small half-cylinder shaped flight inside the drum with the height of $1.5 \mathrm{~cm}$. Motor brand: Transtron. The rotation speed of the drum could be altered between 10 - $60 \mathrm{rpm}$. During all the experiments, the drum was placed at an angle of $10^{\circ}$ up to the horizontal with a hollow PVC board attached. Production of the compost granules for each batch of compost was repeated twice. A compost sample (300 g) was placed in the middle of the drum and the drum was rotated at the desired rotation speed for one minute to pre-mix the feed before a certain weight of binder (desired diluted sodium silicate binder with 0.5 $\mathrm{wt} \%$ polyethylene glycol) was added manually to the compost using a pressure sprayer. For each experiment, the liquid binder was pre-weighed to achieve a targeted liquid binder to compost ratio (weight based, L/S), and sprayed to the moving feed bed at a flow rate of $\sim 400 \mathrm{~mL} / \mathrm{min}$ after compost mixing. After the specific granulation time (the duration of time after compost pre-mixing to the stop of drum rotation), the granules were quickly removed from the drum and dried on trays at room temperature for about two weeks. After drying, all the granules (moisture content around $10 \mathrm{wt} \%$ ) were collected for further analysis. 


\subsection{Properties of materials and granules}

\subsubsection{Proximate analysis}

The moisture content was determined in accordance with the relevant British standard (BS EN 14774-2:2009). Ash content (dry basis) and volatile matter were determined after slow combustion of the samples in a muffle furnace. Finally, the fixed carbon content was calculated by the difference. Gross calorific value of granules (dry basis) was determined according to BS EN 14918:2009 using an oxygen bomb calorimeter (Parr 6200 calorimeter).

\subsubsection{Size distribution}

The product yield was defined as the percentage of the product within a certain size range:

$$
\delta=\frac{M_{T g}}{M_{\text {Total }}} \cdot 100 \%
$$

where, $M_{T g}$ is the mass of granules within the desired size range and $M_{\text {Total }}$ is the total mass of the granules formed. The granules in different size ranges were separated using standard sieves.

\subsubsection{Compressive strength}

The compressive strength of the compost granules $(4.75-6.7 \mathrm{~mm})$ and commercial wood pellets (diameter: $6 \mathrm{~mm}$; length: $15 \mathrm{~mm}$ ) was measured using a TA-XT2i texture analyser (Stable Micro Systems, UK). A single granule was placed in the middle of the flat surface under the metal probe (dia. $35 \mathrm{~mm}$ ) attached to a $2 \mathrm{~kg}$ load cell. A test was then carried out by increasing the applied load at a constant rate of $2 \mathrm{~mm} / \mathrm{s}$ until the granule failed by cracking or breaking. The compressive strength $(\sigma, \mathrm{MPa})$ was then determined from the 
failure load $\left(F_{f}, \mathrm{~N}\right)$ and granule diameter $(D, \mathrm{~mm})$ which was taken as the distance between the plate and the movable probe when the first contact was made between the granule.

$$
\sigma=4 F_{f} / \pi D^{2}
$$

The measurement for each parameter studied was repeated 20 times.

\subsubsection{Bulk density}

Bulk density $\left(\rho_{b}, \mathrm{~kg} / \mathrm{m}^{3}\right)$ is one of significant parameters that describes the properties of granular materials. For the determination of $\rho_{b}$, the compost granules were used to fill a $250 \mathrm{~mL}$ cylinder, and then $\rho_{b}$ was calculated from the mass of bulk granules $\left(W_{g}, \mathrm{~g}\right)$ divided by volume.

$$
\rho_{b}=\frac{W_{g}}{250} \cdot 1000
$$

The bulk density of each parameter studied was measured twice.

\subsubsection{Granule density}

The compost granule density $\left(\rho_{g}, \mathrm{~kg} / \mathrm{m}^{3}\right)$ was measured by a liquid displacement method. The pre-weighed granules $\left(M_{g}, \mathrm{~g}\right)$ around $1 \mathrm{~g}$ with size $4.75-6.7 \mathrm{~mm}$ were added to a graduated cylinder $(10 \mathrm{~mL})$ containing $V_{\text {intial }} \mathrm{mL}$ sunflower oil from a local supplier, and the volume of the granules was equal to the change in volume $\left(V_{\text {after }}-V_{\text {intial }}, \mathrm{mL}\right)$ due to the oil displacement. The volume of the displaced oil is equivalent to volume of the granules added, because the oil did not penetrate into the granules. The granule density $\rho_{g}$ was calculated as below:

$$
\rho_{g}=\frac{M_{g}}{V_{\text {after }}-V_{\text {intial }}} \cdot 1000
$$


The granule density was measured twice.

\subsubsection{Ash melting point}

The ash melting point test was undertaken based on the UK implementation of CEN/TS 15370-1:2006. The ash of each sample was formed in a mould heated at a constant rate and continuously observed for physical change from room temperature to $1500{ }^{\circ} \mathrm{C}$. The temperatures at which characteristic changes of the shape occurred were recorded.

\subsubsection{Water resistance}

The water-resistance properties were tested by water immersion. Granules within the size range $4.75-6.7 \mathrm{~mm}$ from several batches $(2 \mathrm{~g})$ and the commercial wood pellets were immersed in water $(50 \mathrm{~mL})$ for 24 hours at room temperature and the appearance of granules was visually determined and photographed at different time intervals. The wet granules were dried in an oven at $105^{\circ} \mathrm{C}$ overnight. Then the oven-dried granules were collected for compressive strength test. The post compressive strength was used as an indicator for water resistance. Some of the solution after water immersion experiments for different granules was collected for Si content test. 


\section{Results and discussion}

\subsection{Effect of moisture content of initial compost on the physical} properties of compost granules

In this study, Compost A with moisture content of $52 \mathrm{wt} \%, 55 \mathrm{wt} \%, 58 \mathrm{wt} \%$ was used. The drum speed was set at $37 \mathrm{rpm}$ and the granulation time was $15 \mathrm{~min}$ for each batch. Sodium silicate solution ( $3 \mathrm{wt} \%$ ) was used as liquid binder with a fixed L/S 0.77.

Compost granules produced using compost A with $55 \mathrm{wt} \%$ moisture content are shown in Fig. 1, left, and the size distribution of compost granules produced with different moisture content is shown in Fig. 2. It was found that the moisture content of the compost would affect the granulation process and the quality of granules produced. As shown in Fig. 2, with moisture content of compost increasing from $52 \mathrm{wt} \%$ to $58 \mathrm{wt} \%$, more granules with a bigger size were formed and the corresponding equivalent volume diameter $\left(d_{v}, \mathrm{~mm}\right)$ increased over 2.5 times from $2.07 \mathrm{~mm}$ to $5.46 \mathrm{~mm}$. The $d_{v}$ of compost granules was calculated as below, which is the diameter of a sphere with equivalent volume of an irregularly shaped object.

$$
d_{v}=\left[\frac{1}{\sum_{i=1}^{n} x_{i} / d_{i}^{3}}\right]^{1 / 3}
$$

where, $d_{i}$ is the arithmetic mean diameter of the size interval $i(\mathrm{~mm}), x_{i}$ is the weight percentage of compost granules within the size interval $i$. 
For the purpose of this study, it is intended that the granules produced will be used as a fuel for further pyrolysis and combustion study. According to EN 14961-2 and EN 172256, particles with a size under $3.15 \mathrm{~mm}$ are regarded as fines. Due to the diameter of the pyrolysis tube, in this study, granules in the size range between $3.35 \mathrm{~mm}$ and $14 \mathrm{~mm}$ would be considered as the targeted granules. When compost with $52 \mathrm{wt} \%$ moisture content was used, over $50 \mathrm{wt} \%$ of granules formed were under $3.35 \mathrm{~mm}$ and the yield of targeted granules was $46.2 \mathrm{wt} \%$ (Table 1). Increasing the moisture content of compost to $55 \mathrm{wt} \%$ led to over $86 \mathrm{wt} \%$ targeted granules. However, when using compost with $58 \mathrm{wt} \%$ moisture content, coalescence might dominate the process due to partly liquid saturation of compost to form more bigger granules within size $14-20 \mathrm{~mm}$, which then resulted in a lower yield of targeted granules $(78 \mathrm{wt} \%)$. The evidence of the coalescence granules formed during the process is shown in Fig. 3. It was found by Shi et al. that the moisture content in microcrystalline cellulose (MCC) could profoundly affect the wet granulation process and the granule size would increase significantly when water content was increased [21]. The increase in granule size could be explained by the liquid saturation theory in wet granulation, in that coalescence which could lead to rapid growth of granules then started to dominate the granulation process at a certain liquid saturation point $[22,23]$. Using Compost A with $61 \mathrm{wt} \%$ moisture content led to some degree of irregular large clumps being formed during granulation process.

The bulk density and compressive strength of the granules were also measured. As shown in Table 1, when the moisture content of initial compost was increased from $52 \mathrm{wt} \%$ to $58 \mathrm{wt} \%$, the bulk density of the granules produced decreased from $373.1 \mathrm{~kg} / \mathrm{m}^{3}$ to 350.1 $\mathrm{kg} / \mathrm{m}^{3}$. Although the bulk density of the compost granules produced was lower than that 
of commercial wood pellets $\left(>600 \mathrm{~kg} / \mathrm{m}^{3}\right)$ [24], it was higher than that of wood chips $\left(160-255 \mathrm{~kg} / \mathrm{m}^{3}\right)$ [25]. With the increasing of the moisture content from $52 \mathrm{wt} \%$ to 58 $\mathrm{wt} \%$, the compressive strength increased continuously from $0.45 \mathrm{MPa}$ to $0.97 \mathrm{MPa}$, which was similar to or even higher than that of commercial wood pellets $(0.51 \pm$ $0.07 \mathrm{MPa}$ ). With the same amount of compost used for granulation, compost with a higher moisture content had a lower weight percentage of solid materials. Therefore, when the same amount of sodium silicate binder was used, the granules made by compost with the higher moisture content would take up more sodium silicate which could lead to harder granules produced. It was worth noting that due to the diversity of biomass, optimum moisture content range of composts for granulation might vary slightly. Specifically, there is a threshold of moisture content in different biomass waste when the same amount of binder is used to make granules with desired size.

\subsection{Effect of the processing parameters on physical properties of}

\section{compost granules}

Compost B with moisture content of $56 \mathrm{wt} \%$ was used for granulation and sodium silicate binder (3 wt\%) was applied as liquid binder with a fixed L/S 0.77 throughout.

\subsubsection{Effect of the drum speed on the physical properties of compost granules}

Different drum speeds $(22,27,32,37$ and $42 \mathrm{rpm})$ were studied with a granulation time of $15 \mathrm{~min}$. In order to predict the results for drums with different diameters and different scales, the Froude number $(\mathrm{Fr})$ was also determined using the equation below [26]:

$$
F r=\frac{2 \pi^{2} D N^{2}}{3600}
$$


where, $D$ is the drum diameter $(\mathrm{m}), N$ is the rotation speed of the drum (rpm) and $\mathrm{g}$ is gravity acceleration $\left(\mathrm{m} / \mathrm{s}^{2}\right)$.

As shown in Fig. 4, when the drum speed increased from $22 \mathrm{rpm}$ to $37 \mathrm{rpm}$ the yield of granules under size $3.35 \mathrm{~mm}$ decreased from $14.5 \mathrm{wt} \%$ to around $7.5 \mathrm{wt} \%$, whereas the yield of granules within the size range $9.5 \mathrm{~mm}$ to $14 \mathrm{~mm}$ increased from $10 \mathrm{wt} \%$ to 19 $\mathrm{wt} \%$. The increasing rotation speed could also increase the corresponding equivalent volume diameter of the granules $(3.02 \mathrm{~mm}$ to $3.66 \mathrm{~mm})$ and caused the final yield of targeted granules to increase from $81.8 \mathrm{wt} \%$ to $90.5 \mathrm{wt} \%$ (Table 2). This was in an agreement with Thies and Kleinebudde, where increasing rotation speed could generate a bigger mean size of granules $[27,28]$. Increasing the rotation speed of the biomass bed within a certain range could result in the growth of granule size by providing: (1) a better distribution of binder throughout the compost, (2) stronger force for collisions, (3) more opportunities for coalescence.

During granulation, there is one critical rotation speed $\left(S_{c r}, \mathrm{rpm}\right)$ at which material can be carried around the drum by centrifugal action and it corresponds to the speed at which the Froude number is equal to unity [29]:

$$
S_{c r}=\frac{42.4}{\sqrt{D}}
$$

where, $D$ is the drum diameter $(\mathrm{m})$.

The calculated $S_{c r}$ for the drum used in this study was $69 \mathrm{rpm}$, and usually good granulation can be achieved in drums containing no internal flights when rotation speed ranged from $0.3 S_{c r}$ to $0.5 S_{c r}$ [11]. In this study, the optimum rotation speed for compost 
granulation was found between $32 \mathrm{rpm}$ and $37 \mathrm{rpm}$ (corresponding to $0.46-0.53 S_{c r}$ ), which showed the single small flight $(1.5 \mathrm{~cm}$ high) installed in the PVC drum did not have a significant effect on the granulation process.

However, when the rotation speed further increased to $42 \mathrm{rpm}$, some compost would stick to inner wall of the drum and not be employed in the granulation process. Although this rotation speed was under the calculated $S_{c r}(69 \mathrm{rpm})$, the centrifugal phenomenon was still observed. As the sodium silicate binder used could provide additional forces by supporting the adherence of the compost to the inner wall of the drum during granulation process. Thus, the yield of the targeted granules decreased to $69.5 \mathrm{wt} \%$. Even more compost would stick to the inner wall of the drum when a drum rotation speed of $47 \mathrm{rpm}$ was applied, which made the granulation process difficult to proceed.

The bulk densities of compost granules produced with different drum rotational speed were between $330-350 \mathrm{~kg} / \mathrm{m}^{3}$ (Table 2). It was reported that the strength of granule was primarily affected by the porosity of the granule $[15,23]$. Porosity $(\varepsilon)$ of the granule is calculated as below:

$$
\varepsilon=1-\frac{\rho_{g}}{\rho_{T}}
$$

where, $\rho_{g}$ is the granule density $\left(\mathrm{kg} / \mathrm{m}^{3}\right)$ and $\rho_{T}$ is the true density of granule $\left(\mathrm{kg} / \mathrm{m}^{3}\right)$.

By increasing the rotational speed during the granulation process, more consolidation occurred through the collisions amongst the granules themselves and the impacts between the granules and inner walls of the drum. This could reduce the porosity and form much denser granules, thereby increasing the strength of granules. As shown in Table 2, increasing the drum rotational speed from $22 \mathrm{rpm}$ to $42 \mathrm{rpm}$ reduced the porosity of 
compost granules (from $8.1 \%$ to $5.8 \%$ ) and increased the granule strength (from $0.65 \mathrm{MPa}$ to $1.09 \mathrm{MPa})$.

\subsubsection{Effect of the granulation time on the physical properties of compost granules}

Granulation time is also an important parameter in the granulation process and can affect many properties of the produced granules. With the drum rotational speed controlled at $37 \mathrm{rpm}$ throughout, the size distribution of the granules made under different granulation time $(9,12,15,18$ and $21 \mathrm{~min})$ is shown in Fig. 5. Increasing the granulation time from $9 \mathrm{~min}$ to $21 \mathrm{~min}$ improved the yield of the granules with the size range $>4.75 \mathrm{~mm}$ (from $70.7 \mathrm{wt} \%$ to $86.8 \mathrm{wt} \%$ ). Similar to the trend observed in the study of drum rotational speed, the increase of granulation time resulted in the formation of larger granules, which was clearly shown in the corresponding equivalent volume diameters. As in the granulation process, more granulation time would result in more collisions among granules, which could increase the chance of formation of larger granules through coalescence and consolidation mechanisms. Walker et al. also showed that as the granulation time increased, an increase in mean particle size had been found for the fluidised hot melt granulation of lactose [30]. However, further increasing the granulation time to $21 \mathrm{~min}$ resulted in a decrease of targeted granules yield to $89.7 \mathrm{wt} \%$ by forming more larger granules within the size range of $14 \mathrm{~mm}$ to $20 \mathrm{~mm}$.

As shown in Table 3, increasing the granulation time within a certain range could increase the compressive strength of the granules produced but showed no significant difference in the bulk density. When granulation time increased from 9 min to $15 \mathrm{~min}$, the compressive strength slightly increased from $0.74 \mathrm{MPa}$ to $0.98 \mathrm{MPa}$. As stated earlier, 
the granule strength primarily depended on the porosity of granule, and the porosity would decrease exponentially with granulation time due to consolidation [23]. It would be logical to expect the strength of the granules to increase continuously with longer granulation time [31]. However, the compressive strength decreased to $0.91 \mathrm{MPa}$ after 15 min, but this decrease is not statistically significant. Hence in order to achieve a high yield of granules with good strength, 15 min was found to be the optimal granulation time for the compost used in this section.

\subsection{Effect of the binder parameters on the properties of compost}

\section{granules}

Compost $\mathrm{C}$ with moisture content of $58 \mathrm{wt} \%$ was used to make granules. The drum rotational speed and granulation time were controlled at $37 \mathrm{rpm}$ and $15 \mathrm{~min}$, respectively.

\subsubsection{Effect of the binder concentration on the properties of compost granules}

The size distribution of granules made by using different concentrations of sodium silicate binder $(0-9 \mathrm{wt} \%, \mathrm{~L} / \mathrm{S}$ 0.77) is shown in Fig. 6 . With the concentration of sodium silicate binder increasing from $1 \mathrm{wt} \%$ to $9 \mathrm{wt} \%$, the yield of targeted granules dropped significantly and the equivalent volume diameters decreased from $4.17 \mathrm{~mm}$ to $2.02 \mathrm{~mm}$. When $0 \mathrm{wt} \%$ and $1 \mathrm{wt} \%$ sodium silicate binder were used, more granules within the size range $4.75-14 \mathrm{~mm}$ were produced $(>78.4 \mathrm{wt} \%)$. However, as the concentration of binder increased further, the size of granules produced was mainly under $4.75 \mathrm{~mm}(>62.8 \mathrm{wt} \%)$.

It was reported that the viscosity of binder could be a key factor in the wet granulation process $[13,23,32]$. However, the viscosities of the sodium silicate binders used here 
were all around $5 \mathrm{mPa}^{*} \mathrm{~s}$, which might not be a critical role in this case. To further validate the results obtained, Stokes deformation number $\left(S t_{d e f}\right)$ for granulation processes using different concentrations of sodium silicate binders were calculated (Table 4). The $S t_{d e f}$ reflects the ratio of externally applied kinetic energy in the system to the energy required for deformation of the granules and it is given as below [26, 33]:

$$
S t_{d e f}=\frac{\rho_{g} v^{2}}{2 \sigma_{s}}
$$

where $\rho_{g}$ is the density of granule $\left(\mathrm{kg} / \mathrm{m}^{3}\right) ; \sigma_{s}$ is the dynamic strength of the granule $(\mathrm{Pa})$ and $v$ is the collision velocity of the granule $(\mathrm{m} / \mathrm{s})$.

The dynamic strength of the granule is calculated as below:

$$
\sigma_{S}=\frac{9}{8} \frac{(1-\varepsilon)^{2}}{\varepsilon^{2}} \frac{9 \pi \mu v_{p}}{16 m}
$$

where $\mu$ is the viscosity of sodium silicate solution $\left(\mathrm{Pa}^{*} \mathrm{~s}\right) ; d_{m}$ is surface mean diameter of primary compost $(\mathrm{m}) ; \varepsilon$ is the porosity of the granule and $v_{p}$ is the relative velocity of the moving particles during granulation process $(\mathrm{m} / \mathrm{s}) .10 \%$ of the linear rotation speed of the drum is assumed to be the $v_{p}$.

The $\sigma_{s}$ and $S t_{d e f}$ based on different concentrations of sodium silicate binders were shown in Table 4. During the granulation process, as the concentration of sodium silicate binder increased from $1 \mathrm{wt} \%$ to $9 \mathrm{wt} \%$, the $\sigma_{s}$ of granules increased from $52.7 \mathrm{~Pa}$ to $428.2 \mathrm{~Pa}$ and the $S t_{d e f}$ decreased from 2.16 to 0.32 . A higher $S t_{d e f}$ meant easier deformation for granules produced during granulation process, some binder in these granules was easily squeezed out facilitating the particles or materials to achieve granules with larger diameter. 
With higher concentration of sodium silicate binder used, the bulk density increased from $240.7 \mathrm{~kg} / \mathrm{m} 3$ to $453.3 \mathrm{~kg} / \mathrm{m}^{3}$ and the compressive strength of granules increased from 0.77 $\mathrm{MPa}$ to $3.00 \mathrm{MPa}$ (Table 5). After water immersion, all the granules produced using granulation method remain their original shape. Whereas, the commercially available wood pellets fell apart after 10 min water immersion test (Fig. S1, ESI). Compared with their initial compressive strength, we observed a decrease in the post compressive strength. However, the use of sodium silicate binder could improve the post compressive strength. As shown in Table 5, the post compressive strength of granules made without sodium silicate was only $0.15 \mathrm{MPa}$, whereas, the granules that produced using sodium silicate binder remained post compressive strength over $0.30 \mathrm{MPa}$. It was reported that the drying temperature of agglomerates had an important influence on the consolidation of sodium silicate. The dehydration of sodium silicate binder in less than $550{ }^{\circ} \mathrm{C}$ did not provide total insolubility of the sodium silicate in water $[18,34]$. Therefore, the difference between the initial and the post compressive strength of the granules might be caused by the structure weakening of sodium silicate during the water immersion experiment, which was further confirmed by the difference of $\mathrm{Si}$ content in the solution after water immersion experiments for different granules (Table S2).

Higher sodium silicate could also influence the burning quality by producing higher ash content, lowering calorific value and ash melting point, which could affect the overall efficiency of combustion for fuel energy purpose. The gross calorific value of granules made without sodium silicate was $17.7 \mathrm{MJ} / \mathrm{kg}$. With the concentration of sodium silicate solution increasing from $1 \mathrm{wt} \%$ to $9 \mathrm{wt} \%$, the calorific value dropped linearly from 17.5 
$\mathrm{MJ} / \mathrm{kg}$ to $15.1 \mathrm{MJ} / \mathrm{kg}$ (Fig. S2) and the ash content increased significantly from $19.9 \%$ to $33.3 \%$. The ash melting point of compost granules were also investigated and showed a linearly decreasing trend with the increase of concentration of sodium silicate solution (Fig. S3). Thus, the amount of sodium silicate used needs to be controlled carefully to match the usage purpose.

\subsubsection{Effect of the binder to solid ratio $(\mathrm{L} / \mathrm{S})$ on the properties of compost granules}

The concentration of sodium silicate solution applied was $3 \mathrm{wt} \%$, and the $\mathrm{L} / \mathrm{S}$ was controlled at $0.63,0.70,0.77,0.83$ and 0.90 . Increasing the $\mathrm{L} / \mathrm{S}$ could increase the availability of binder for agglomeration. Therefore, increasing this variable should result in an overall increase in the mean size of the granules produced (Fig. 7). With the increase of $\mathrm{L} / \mathrm{S}$ from 0.63 to 0.90 , the yield of targeted granules was drastically improved from $22.1 \mathrm{wt} \%$ to $85.9 \mathrm{wt} \%$, and the equivalent volume diameter was nearly doubled from 1.92 $\mathrm{mm}$ to $3.64 \mathrm{~mm}$. More granules with a size under $3.35 \mathrm{~mm}$ were produced when a lower L/S was used. These findings were consistent with the literature, where the granule size was found to be very sensitive to binder to solid ratio [35, 36, 37]. Higher L/S 0.97 was also tried to make granules, some small lumps were formed during the experiments. Further excessive amounts of binder would result in paste formation, which would impede the agglomeration process [38]. So there is a threshold beyond which further increasing the liquid binder will result in over-growth of particles hence reducing the final product yield, and different materials may have a different threshold.

From Table 6, when a L/S 0.77 was applied, the granules produced had a maximum bulk density of $318.7 \mathrm{~kg} / \mathrm{m}^{3}$. When the liquid to solid ratio was increased from 0.63 to 0.90 , 
the initial compressive strength was raised by almost two times from $0.99 \mathrm{MPa}$ to 1.75 MPa. During the granulation process, droplets of sodium silicate solution formed bridges between the primary compost particles, and after drying, the liquid bridges became solidified and formed solid bridges that gave the strength of compost granules produced. Changing the binder to compost ratio (L/S) would affect the strength and number of bonds formed between the primary particles, which in turn affect the overall strength of granules formed [38]. A higher L/S would result in granules produced having higher ash content and lower calorific value for combustion (Table 6). The ash content of granules increased slightly from $21.1 \%$ to $22.5 \%$ with increasing $\mathrm{L} / \mathrm{S}$ from 0.63 to 0.90 and the calorific value dropped slightly from $17.4 \mathrm{MJ} / \mathrm{kg}$ to $16.1 \mathrm{MJ} / \mathrm{kg}$. Compared with the gross calorific values of oven-dried woody biomass, which are typically around 17 to $21 \mathrm{MJ} / \mathrm{kg}$ [39], we were glad to see that compost granules produced in this study have competitive values and they have the potential to be used as a kind of solid biofuel.

The results of this study show that the initial moisture content of the compost could significantly affect the size distribution of granules produced in comparison to drum speed and granulation time. It was also found that the concentration of sodium silicate binder and L/S played important role in controlling the properties of produced granules. Higher concentrations of sodium silicate binder and L/S used would lead to compost granules produced with higher compressive strength and water resistance, whereas, the calorific value and ash melting point would decrease significantly. In order to make granules with competitive properties when compared with woody biomass fuels, $1-3 \mathrm{wt} \%$ sodium silicate binder and L/S $(0.77-0.90)$ were found to be the optimal conditions. 


\section{Conclusions}

Compost, as a model bio-waste, was successfully densified into good-quality spherical granules using drum granulation with low-cost sodium silicate solution as binder for the purpose of convenient storage and transportation. This study clearly showed it was possible to use silicate-based binders to make bio-waste granules through drum granulation process, and the granules produced has the potential to be used as solid biofuel compared with woody fuels. Further studies which adopt this granulation method with sodium silicate binder for the production of granules using other bio-waste and their applications (combustion, pyrolysis, heavy metal absorption) are currently underway within our group.

\section{Acknowledgements}

This project was funded by the Centre for Advanced Sustainable Energy (CASE) through Invest Northern Ireland's Competence Centre programme. 


\section{Reference}

[1] A. Demirbaş, Biomass resource facilities and biomass conversion processing for fuels and chemicals, Energy Conversion and Management. 42 (2001) 1357-1378.

[2] E.G.A. Forbes, D.L. Easson, G.A. Lyons, W.C. McRoberts, Physico-chemical characteristics of eight different biomass fuels and comparison of combustion and emission results in a small scale multi-fuel boiler, Energy Conversion and Management. 87 (2014) 1162-1169.

[3] S. Nakada, D. Saygin, D. Gielen, Global bioenergy supply and demand projections: a working paper for REmap 2030. International Renewable Energy Agency (IRENA). (2014) 1-88.

[4] M. Fatih Demirbas, M. Balat, H. Balat, Biowastes-to-biofuels, Energy Conversion and Management. 52 (2011) 1815-1828.

[5] F. Fava, G. Totaro, L. Diels, M. Reis, J. Duarte, O.B. Carioca, et al., Biowaste biorefinery in Europe: opportunities and research \& development needs, New Biotechnology. 32 (2015) 100-108.

[6] C. Nzila, J. Dewulf, H. Spanjers, H. Kiriamiti, H. van Langenhove, Biowaste energy potential in Kenya, Renewable Energy. 35 (2010) 2698-2704.

[7] Department of Energy and Climate Change, Renewable Heat Incentive (RHI) Scheme. https://www.gov.uk/government/publications/2010-to-2015-government-policy-low-carbontechnologies/2010-to-2015-government-policy-low-carbon-technologies\#appendix-6-renewable-heatincentive-rhi, accessed November 1, 2018.

[8] P. McKendry, Energy production from biomass (part 1): overview of biomass, Bioresource Technology. 83 (2002) 37-46.

[9] W. Pietsch, Chapter 4: Industrial size enlargement equipment and processes. Size enlargement by agglomeration, Wiley, New York. 1991.

[10] W. Pietsch, Chapter 5: Industrial applications of agglomeration. Size enlargement by agglomeration, Wiley, New York. 1991. 
[11] Y. Ghasemi, M.H. Kianmehr, A.H. Mirzabe, B. Abooali, The effect of rotational speed of the drum on physical properties of granulated compost fertilizer, Physicochemical Problems of Mineral Processing. 49 (2013) 743-755.

[12] Y. Ghasemi, M.H. Kianmehr, The effect of filling of the drum on physical properties of granulated multicomponent fertilizer, Physicochemical Problems of Mineral Processing. 52 (2016) 575-587.

[13] V. Yandapalli, S. Mani, Wet granulation of pine wood powders, American Society of Agricultural and Biological Engineers. 57 (2014) 1211-1218.

[14] V. Yandapalli, S. Mani, Effect of lime pretreatment on granulation of switchgrass, Bioenergy Research. 7 (2014) 833-844.

[15] B. Bowden-Green, L. Briens, An investigation of drum granulation of biochar powder, Powder Technology. 288 (2016) 249-254.

[16] H.E. Bergna, W.O. Roberts, Colloidal silica: fundamentals and applications, Taylor \& Francis Group, LLC. 2006

[17] M. McDonald, J. Hamilton, Recent developments in soluble silicate based binders and coatings. Conference Proceedings. Institute for Briquetting and Agglomeration. 2007.

[18] F. De Castro Dutra, M. Emrich, G. Magela da Costa, A. Dias, Influence of drying temperature and atmosphere on the mechanical strength of iron-ore agglomerates and sodium silicates for application in sintering processes, The Canadian Journal of Chemical Engineering. 94 (2016) 75-80.

[19] C.T. Keeley, Sodium silicate: The key ingredient in detergent agglomeration, Journal of the American Oil Chemists' Society. 60 (1983) 1370-1372.

[20] F.D. Snell, C.S. Kimball, Briquetting Coal with Sodium Silicate, Industrial and Engineering Chemistry. 29 (1937) 724-726.

[21] L. Shi, Y. Feng, C.C. Sun, Initial moisture content in raw material can profoundly influence high shear wet granulation process, International Journal of Pharmaceutics. 416 (2011) 43-48.

[22] S.I.F. Badawy, T.J. Lee, M.M. Menning, Effect of drug substance particle size on the characteristics of granulation manufactured in a high-shear mixer, AAPS PharmSciTech. 1 (2000) article 33.

[23] S.M. Iveson, J.D. Litster, K. Hapgood, B.J. Ennis, Nucleation, growth and breakage phenomena in agitated wet granulation processes: a review, Powder Technology. 117 (2001) 3-39. 
[24] European Pellet Council, Quality certification scheme for wood pellets, Part 3: Pellet quality requirements. ENplus Handbook, version 3.0. 2015.

[25] A. Gendek, M. Aniszewska, K. Chwedoruk, Bulk density of forest energy chips, Agricultural and Forest Engineering. 67 (2016) 101-111.

[26] Y.N. Baghdadi, R.K. Shah, A.B. Albadarin, C. Mangwandi, Growth kinetics of nuclei formed from different binders and powders in vertical cylindrical mixing devices, Chemical Engineering Research and Design. 132 (2018) 1070-1081.

[27] R. Thies, P. Kleinebudde, Melt pelletisation of a hygroscopic drug in a high shear mixer, International Journal of Pharmaceutics. 188 (1999) 131-143.

[28] R. Thies, P. Kleinebudde, Melt pelletisation of a hygroscopic drug in a high shear mixer, European Journal of Pharmaceutical Sciences. 10 (2000) 103-110.

[29] G.M. Walker, Chapter 4 Drum granulation processes. Granulation, edited by Salman, A.D., Hounslow, M.J., Seville, J.P.K. Handbook of powder technology. 11(2007) 219-254.

[30] G.M. Walker, C.R. Holland, M.M.N. Ahmad, D.Q.M. Craig, Influence of process parameters on fluidised hot-melt granulation and tablet pressing of pharmaceutical powders, Chemical Engineering Science. 60 (2005) 3867-3877.

[31] C. Mangwandi, M.J. Adams, M.J. Hounslow, A.D. Salman, An investigation of the influence of process and formulation variables on mechanical properties of high shear granules using design of experiment, International Journal of Pharmaceutics. 427 (2012) 328-336.

[32] A.A. Adetayo, J.D. Litster, M. Desai, The effect of process parameters on drum granulation of fertilizers with broad size distributors, Chemical Engineering Science. 48 (1993) 3951-3961.

[33] K. van den Dries, H. Vromans, Relationship between inhomogeneity phenomena and granule growth mechanisms in a high-shear mixer, International Journal of Pharmaceutics. 247 (2002) 167-177.

[34] S. Lucas, M.T. Tognonvi, J.-L. Gelet, J. Soro, S. Rossignol, Interactions between silica sand and sodium silicate solution during consolidation process, Journal of Non-Crystalline Solids. 357 (2011) $1310-1318$.

[35] W. Chansataporn, M. Nopharatana, Effects of binder content and drum filling degree on cassava pearl granulation using drum granulator, Asian Journal of Food and Agro-Industry. 2 (2009) 739-748. 
[36] C. Mangwandi, L. JiangTao, A.B. Albadarin, R.M. Dhenge, G.M. Walker, High shear granulation of binary mixtures: Effect of powder composition on granule properties, Powder Technology. 270 (2015) 424-434.

[37] R. Ramachandran, J.M.H. Poon, C.F.W. Sanders, T. Glaser, C.D. Immanuel, F.J. Doyle III, et al., Experimental studies on distributions of granule size, binder content and porosity in batch drum granulation: Inferences on process modelling requirements and process sensitivities, Powder Technology. 188 (2008) 89-101.

[38] C. Mangwandi, L. JiangTao, A.B. Albadarin, S.J. Allen, G.M. Walker, Alternative method for producing organic fertiliser from anaerobic digestion liquor and limestone powder: High Shear wet granulation, Powder Technology. 233 (2013) 245-254.

[39] C. Telmo, J. Lousada, N. Moreira, Proximate analysis, backwards stepwise regression between gross calorific value, ultimate and chemical analysis of wood, Bioresource Technology. 101 (2010) 38083815. 
Table 1: Physical properties of granules produced by compost with different moisture content

\begin{tabular}{cccc}
\hline & \multicolumn{3}{c}{ Moisture content of compost } \\
\cline { 2 - 3 } Properties of granules & $52 \mathrm{wt} \%$ & $55 \mathrm{wt} \%$ & $58 \mathrm{wt} \%$ \\
\hline Yield of targeted granules $[\mathrm{wt} \%]^{[\mathrm{a}]}$ & $46.2(3.3)$ & $86.1(1.4)$ & $78.2(2.4)$ \\
Bulk density $\left[\mathrm{kg} / \mathrm{m}^{3}\right]^{[\mathrm{a}]}$ & $373.1(2.7)$ & $372.6(1.5)$ & $350.1(4.2)$ \\
Compressive strength $[\mathrm{MPa}]^{[\mathrm{b}]}$ & $0.45(0.08)$ & $0.67(0.14)$ & $0.97(0.14)$ \\
\hline
\end{tabular}

[a] Values are the average of two replicates

[b] Values in parentheses are standard deviation for $\mathrm{n}=20$.

Table 2: Physical properties of granules produced under different drum speed

\begin{tabular}{cccccc}
\hline & \multicolumn{5}{c}{ Drum rotation speed } \\
\cline { 2 - 6 } Properties of granules & $22 \mathrm{rpm}$ & $27 \mathrm{rpm}$ & $32 \mathrm{rpm}$ & $37 \mathrm{rpm}$ & $42 \mathrm{rpm}$ \\
\hline Yield of targeted granules $[\mathrm{wt} \%]^{[\mathrm{a}]}$ & $81.8(2.3)$ & $87.8(1.5)$ & $90.5(1.3)$ & $90.2(0.2)$ & $69.5(1.0)$ \\
Bulk density $\left[\mathrm{kg} / \mathrm{m}^{3}\right]^{[\mathrm{a}]}$ & $340.2(3.4)$ & $344.5(2.6)$ & $345.0(2.1)$ & $342.3(1.7)$ & $333.3(1.8)$ \\
Compressive strength $[\mathrm{MPa}]^{[\mathrm{b}]}$ & $0.65(0.14)$ & $0.85(0.16)$ & $0.91(0.14)$ & $0.98(0.15)$ & $1.09(0.17)$ \\
Porosity $[\%]^{[\mathrm{a}]}$ & $8.1(0.2)$ & $7.7(0.2)$ & $7.2(0.3)$ & $6.6(0.2)$ & $5.8(0.3)$ \\
\hline
\end{tabular}

[a] Values are the average of two replicates

[b] values in parentheses are standard deviation for $\mathrm{n}=20$.

Table 3: Physical properties of granules produced under different granulation time

\begin{tabular}{cccccc}
\hline & \multicolumn{5}{c}{ Granulation time } \\
\cline { 2 - 6 } Properties of granules & 9 min & 12 min & 15 min & 18 min & 21 min \\
\hline Yield of targeted granules $[\mathrm{wt} \%]^{[\mathrm{a}]}$ & $84.0(0.1)$ & $87.0(2.2)$ & $90.2(0.2)$ & $91.2(1.8)$ & $89.7(1.2)$ \\
Bulk density $\left[\mathrm{kg} / \mathrm{m}^{3}\right]^{[\mathrm{a}]}$ & $340.1(0.7)$ & $340.6(1.4)$ & $342.3(1.7)$ & $344.63(1.0)$ & $343.9(1.6)$
\end{tabular}


[a] Values are the average of two replicates

[b] values in parentheses are standard deviation for $n=20$.

Table 4: The dynamic strength and $S t_{d e f}$ number of different granules

\begin{tabular}{ccccccc}
\hline & \multicolumn{6}{c}{ Concentration of sodium silicate binder } \\
\cline { 2 - 7 } & $0 \mathrm{wt} \%$ & $1 \mathrm{wt} \%$ & $3 \mathrm{wt} \%$ & $5 \mathrm{wt} \%$ & $7 \mathrm{wt} \%$ & $9 \mathrm{wt}^{0} \%$ \\
\hline Dynamic strength [Pa] & 35.3 & 52.7 & 59.5 & 116.5 & 320.9 & 428.2 \\
$S t_{\text {def }}$ & 3.12 & 2.16 & 1.98 & 1.07 & 0.41 & 0.32 \\
\hline
\end{tabular}

Table 5: Properties of compost granules produced with different binder concentrations

\begin{tabular}{|c|c|c|c|c|c|c|}
\hline \multirow[b]{2}{*}{ Properties of granules } & \multicolumn{6}{|c|}{ Concentration of sodium silicate binder } \\
\hline & $0 \mathrm{wt} \%$ & $1 \mathrm{wt} \%$ & $3 \mathrm{wt} \%$ & $5 \mathrm{wt} \%$ & $7 \mathrm{wt} \%$ & $9 \mathrm{wt} \%$ \\
\hline Yield of targeted granules [wt $\%]^{[\mathrm{a}]}$ & $90.4(0.9)$ & $91.1(2.6)$ & $61.0(4.5)$ & $51.4(1.8)$ & $40.7(1.9)$ & $37.1(1.8)$ \\
\hline Bulk density $\left[\mathrm{kg} / \mathrm{m}^{3}\right]^{[\mathrm{a}]}$ & $240.7(3.5)$ & $262.0(5.2)$ & $318.7(2.2)$ & $366.8(4.3)$ & $402.6(12.4)$ & $453.3(5.8)$ \\
\hline Compressive strength $[\mathrm{MPa}]^{[\mathrm{b}]}$ & $0.77(0.12)$ & $0.97(0.16)$ & $1.33(0.15)$ & $1.82(0.21)$ & $2.43(0.25)$ & $3.00(0.17)$ \\
\hline Post compressive strength $[\mathrm{MPa}]^{[\mathrm{c}]}$ & $0.15(0.04)$ & $0.30(0.08)$ & $0.36(0.12)$ & $0.38(0.12)$ & $0.35(0.13)$ & $0.34(0.13)$ \\
\hline Gross calorific value $[\mathrm{MJ} / \mathrm{kg}]^{[\mathrm{d}]}$ & $17.7(0.4)$ & $17.5(0.1)$ & $17.0(0.5)$ & $16.0(0.4)$ & $15.1(0.30)$ & $15.1(0.3)$ \\
\hline Ash content $[\%]^{[\mathrm{a}]}$ & $17.2(0.2)$ & $19.9(0.3)$ & $22.1(0.9)$ & $25.5(1.1)$ & $28.7(0.9)$ & $33.3(1.5)$ \\
\hline
\end{tabular}

\section{[a] Values are the average of two replicates}

[b] Granules before water resistance test were used and values in parentheses are standard deviation for $\mathrm{n}=20$.

[c] Granules after water resistance test were used and values in parentheses are standard deviation for $\mathrm{n}=20$.

[d] Values in parentheses are standard deviation for $\mathrm{n}=3$. 
Table 6: Properties of compost granules produced with different binder to solid ratio

\begin{tabular}{|c|c|c|c|c|c|}
\hline \multirow[b]{2}{*}{ Properties of granules } & \multicolumn{5}{|c|}{ Binder to solid ratio $(\mathrm{L} / \mathrm{S})$} \\
\hline & 0.63 & 0.70 & 0.77 & 0.83 & 0.90 \\
\hline Yield of targated granules $[\mathrm{wt} \%]^{[\mathrm{a}]}$ & $22.1(3.5)$ & $34.3(2.8)$ & $61.0(4.5)$ & $73.6(4.6)$ & $85.9(5.2)$ \\
\hline Bulk density $\left[\mathrm{kg} / \mathrm{m}^{3}\right]^{[\mathrm{a}]}$ & $294.5(5.4)$ & $307.6(3.5)$ & $318.7(2.2)$ & $312.3(0.8)$ & $309.4(3.2)$ \\
\hline Compressive strength $[\mathrm{MPa}]^{[\mathrm{b}]}$ & $0.99(0.19)$ & $1.09(0.12)$ & $1.33(0.15)$ & $1.52(0.26)$ & $1.75(0.23)$ \\
\hline Post compressive strength $[\mathrm{MPa}]^{[\mathrm{c}]}$ & $0.30(0.09)$ & $0.31(0.07)$ & $0.36(0.12)$ & $0.39(0.12)$ & $0.46(0.10)$ \\
\hline Gross calorific value $[\mathrm{MJ} / \mathrm{kg}]^{[\mathrm{d}]}$ & $17.4(0.2)$ & $17.2(0.3)$ & $17.0(0.5)$ & $16.6(0.1)$ & $16.1(0.1)$ \\
\hline Ash content $[\%]^{[\mathrm{a}]}$ & $21.1(0.7)$ & $21.2(0.9)$ & $22.1(0.9)$ & $22.1(1.5)$ & $22.5(1.2)$ \\
\hline
\end{tabular}

[a] Values are the average of two replicates

[b] Granules before water resistance test were used and values in parentheses are standard deviation for $\mathrm{n}=20$.

[c] Granules after water resistance test were used and values in parentheses are standard deviation for $\mathrm{n}=20$.

[d] Values in parentheses are standard deviation for $\mathrm{n}=3$. 


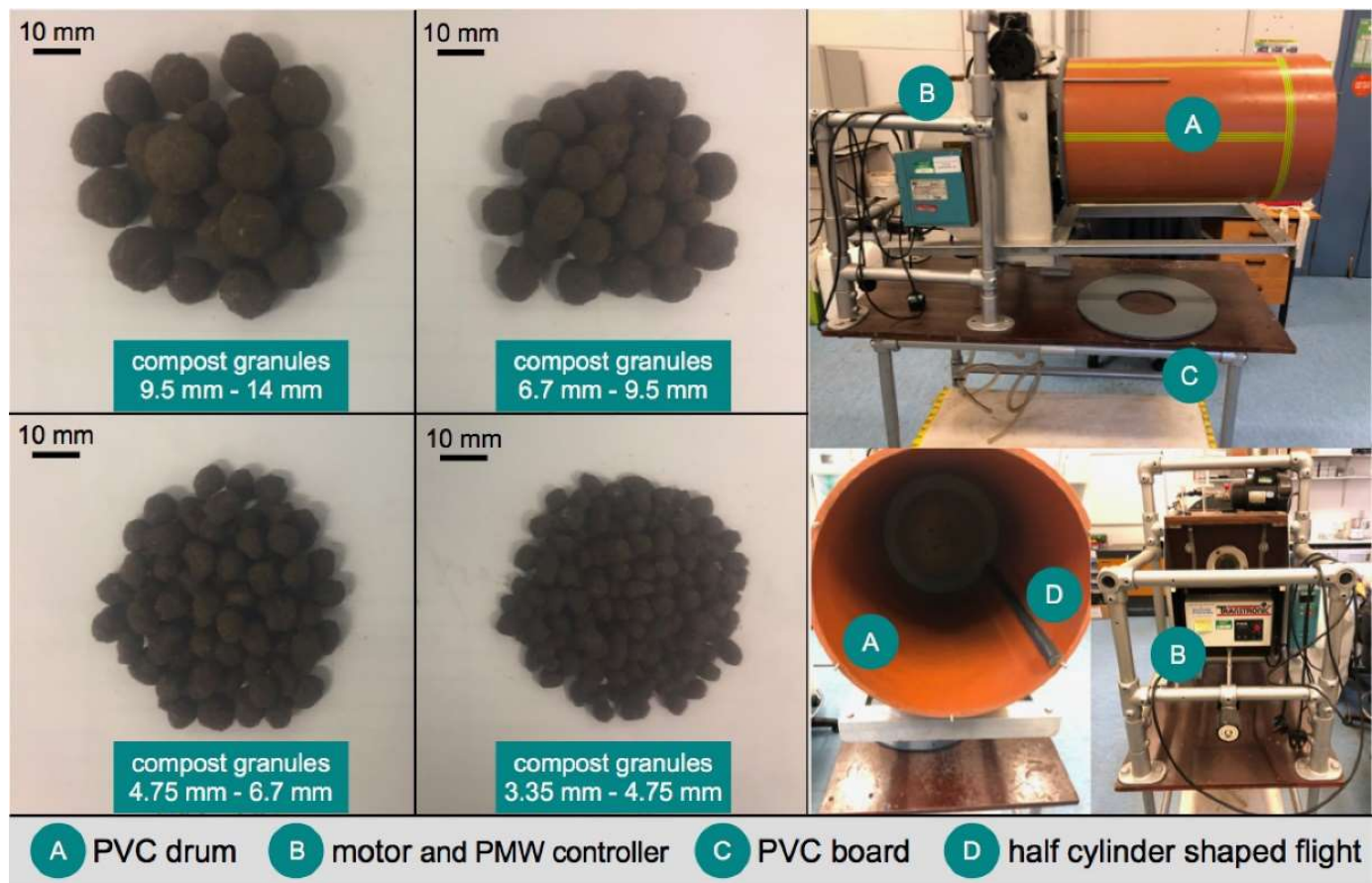

Fig. 1 Examples of compost granules (left) with different size ranges and drum granulator (right)

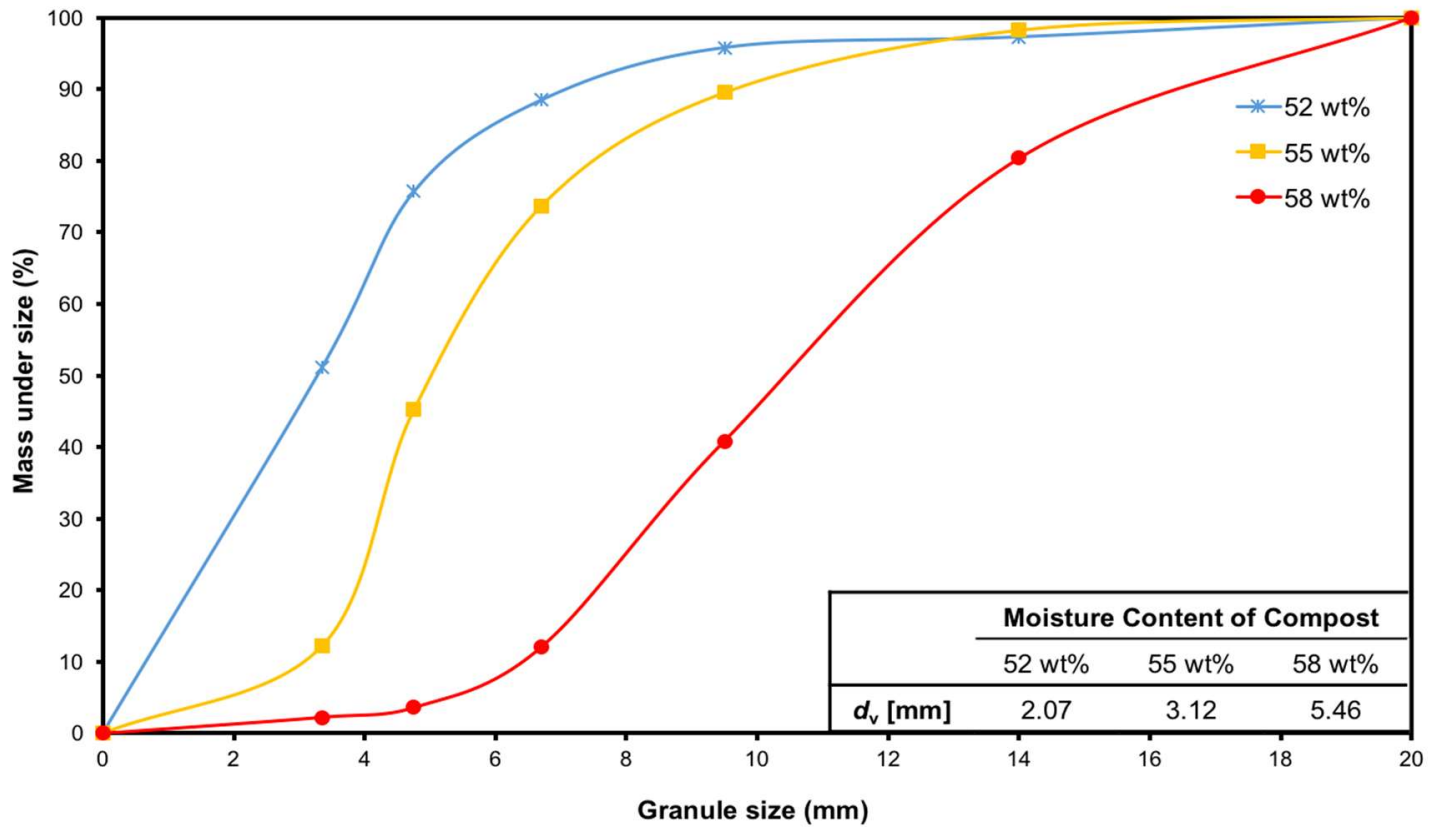


Fig. 2 Effect of moisture content of compost A on the size distribution of granules produced

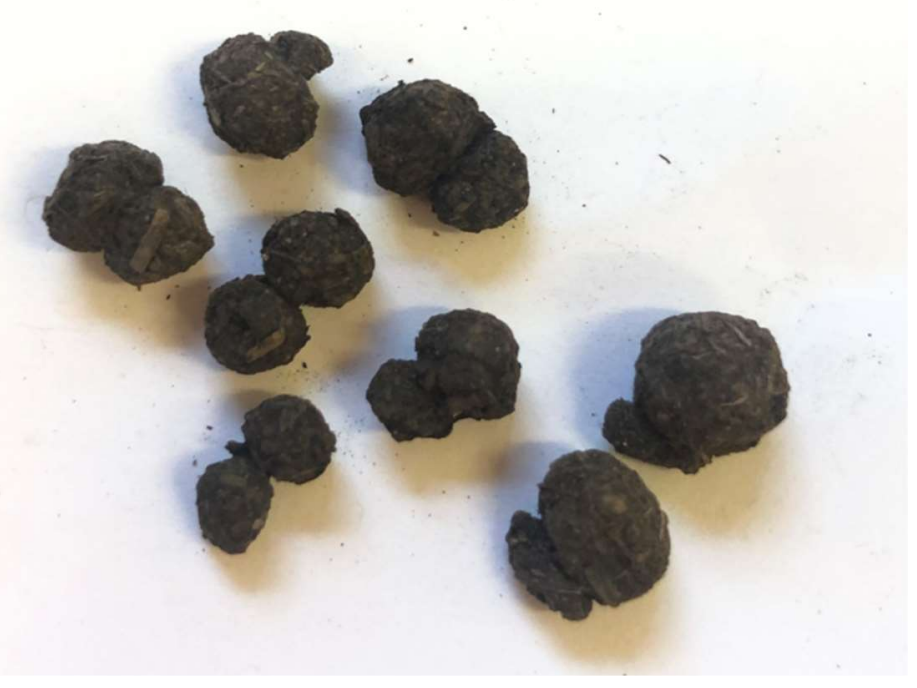

Fig. 3 The coalescence granules formed during the granulation process

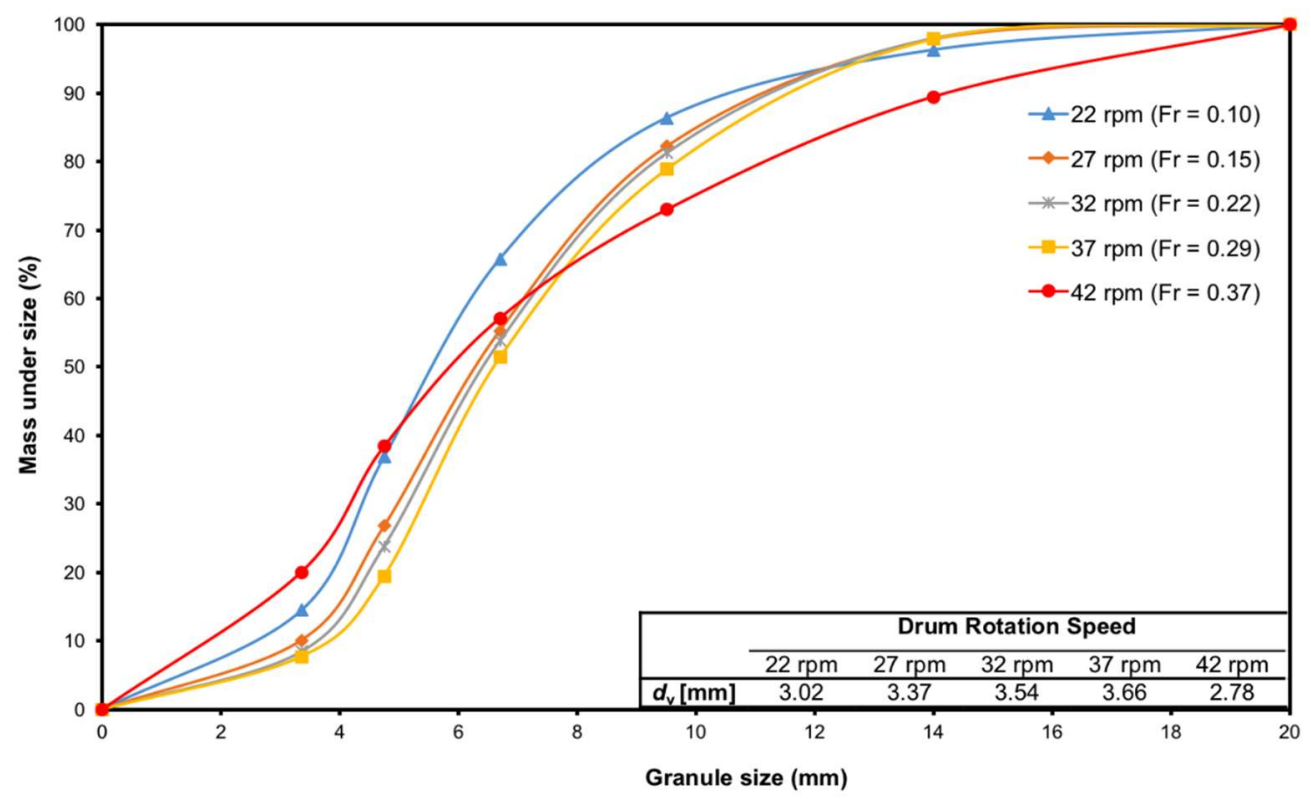

Fig. 4 Effect of drum speed on the size distribution of granules produced 


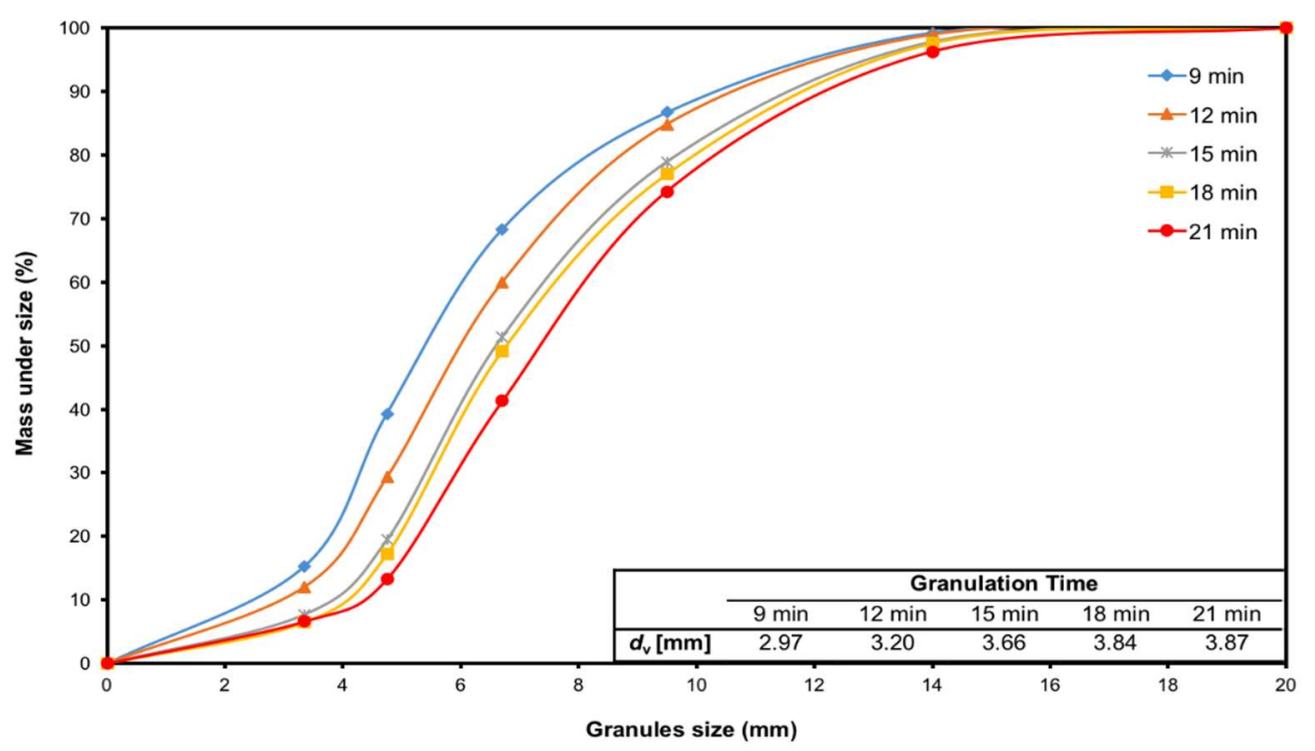

Fig. 5 Effect of the granulation time on the size distribution of granules produced

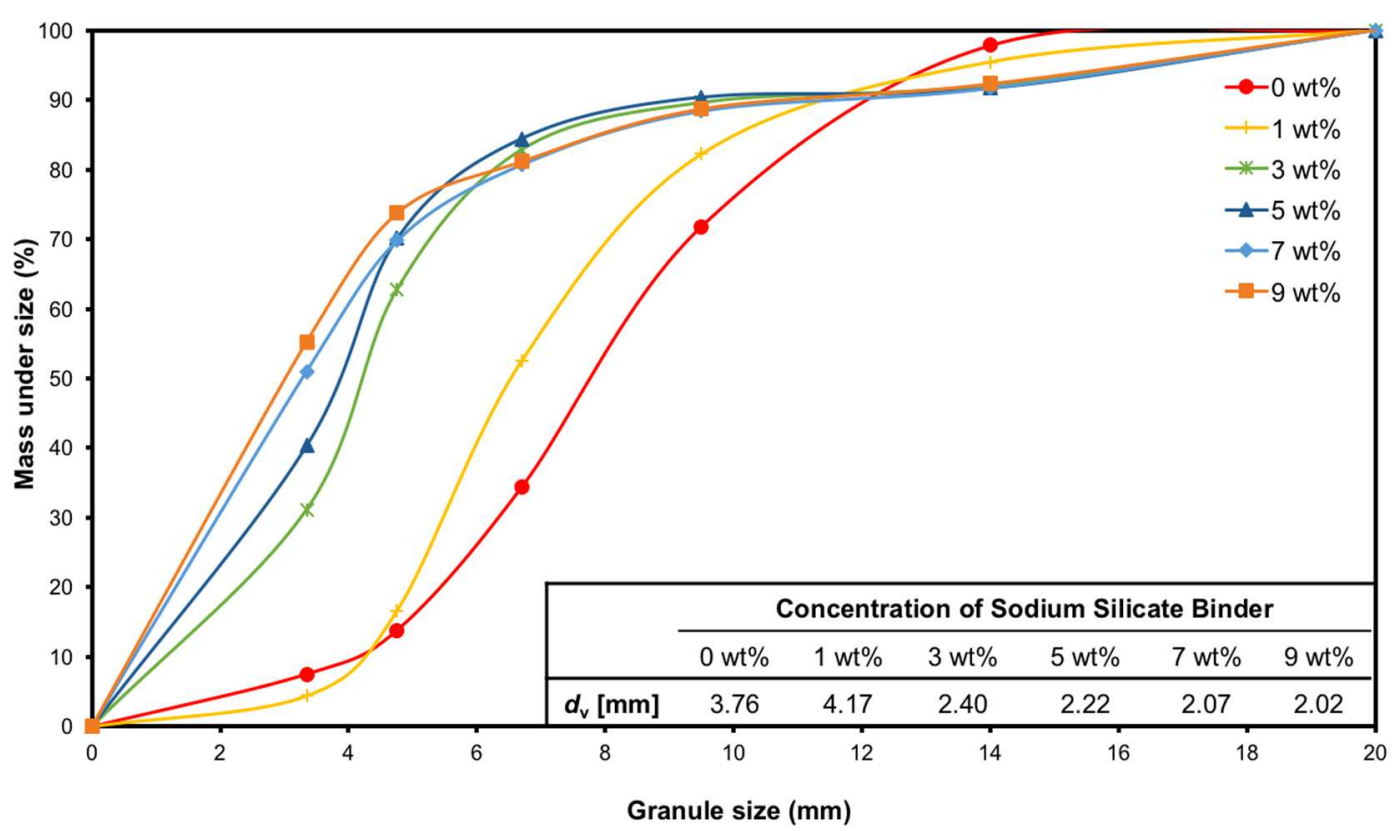

Fig. 6 Effect of the binder concentration on the size distribution of granules produced 


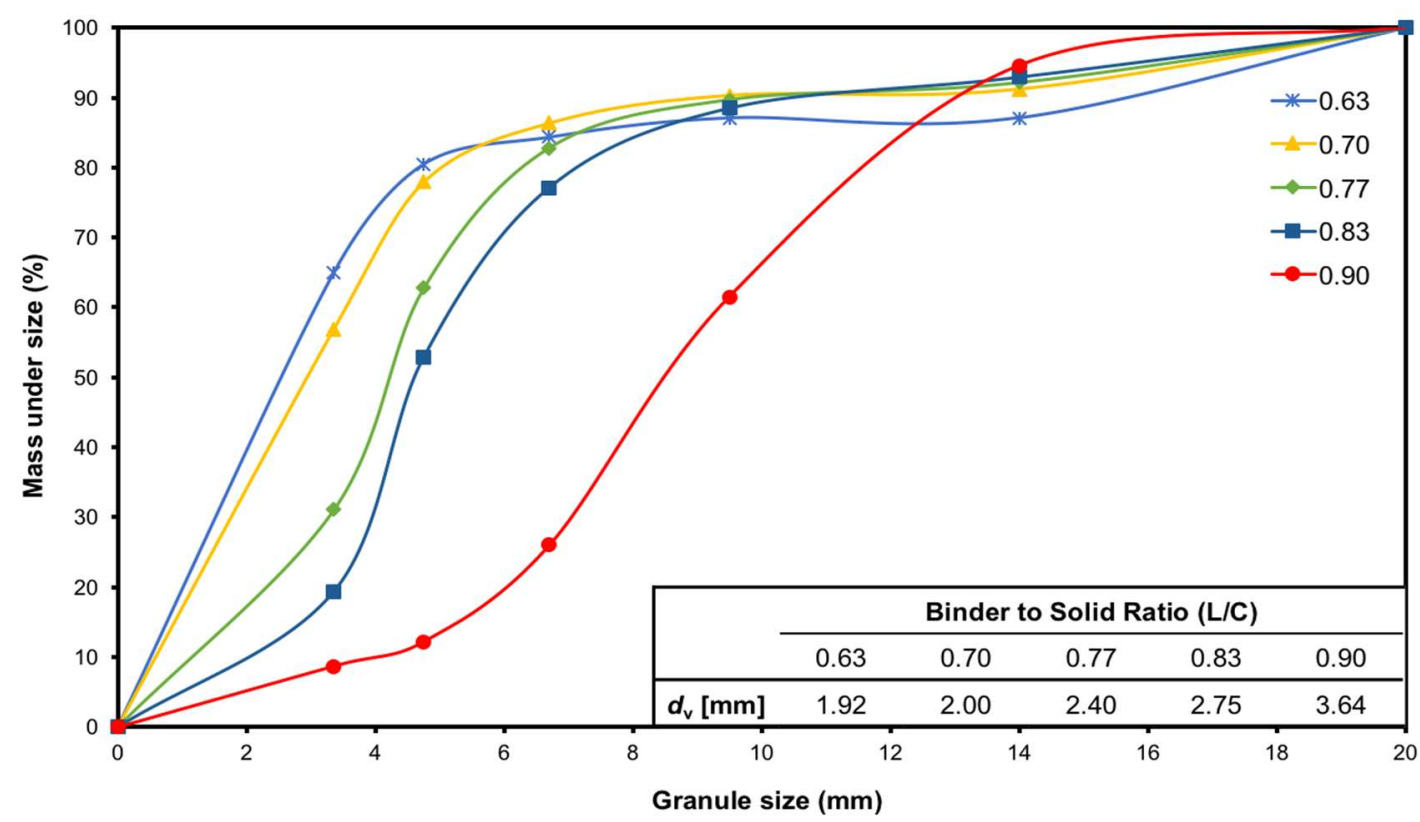

Fig. 7 Effect of the binder to solid ratio on the size distribution of granules produced 